\title{
Meteorological and hydrological drought monitoring using several drought indices
}

\author{
Hana Salimi ${ }^{1} \cdot$ Esmail Asadi $^{1} \cdot$ Sabereh Darbandi $^{1}$
}

Received: 15 October 2019 / Accepted: 15 December 2020 / Published online: 14 January 2021

(c) The Author(s) 2021

\begin{abstract}
With respect to the necessity of comprehensive studies on drought and also high damages that caused by drought, this research studied the meteorological and hydrological droughts. In this study, Lighvan, Navroud and Seqez basins with different climates were selected. We used monthly data of stream flow, precipitation and evaporation from 1992 to 2016 for the study of drought phenomena. The aim at this study is to analyze the SPI and SPEI for determination of dry and wet meteorological periods and use of the SSI for the exploration of hydrological drought. The analysis of drought characteristics such as intensity and duration in three areas with different climates shows that the climate change has a major impact on the characteristics of the droughts. The relations between the duration and severity of drought have been more accurate in the period of 9 months in the Navroud watershed basin. The most significant events are SPI-9 with the duration of 57 months and the severity of 34.7, SPEI-9 with the duration of 34 months and the severity of 28.09 and SSI-9 with the duration of 41 months and the severity of 30.2. According to the obtained equations in different time periods, it was resulted that the highest accuracy was observed in the relationship between the meteorological and hydrological drought characteristics in the watershed basin of Seqez for a period of 6 months. The results show that in all three basins, the correlation between the meteorological and hydrological drought is significant at the level of $99 \%$. Results show that hydrological and meteorological droughts in Navroud and Lighvan basins have a significant correlation with 48-month periods and in the Seqez basin with 12- and 24-month periods, and the relations between hydrological droughts and meteorological droughts were obtained using the nonlinear linear models (polynomial, exponential and logarithmic). The good $R^{2}$ between the duration and severity of SPI-9 and SSI-9 is 0.8 and 0.92 , respectively, for polynomial equations. The maximum determination coefficient of duration and severity of SPEI-9 and SSI-9 is 0.72 and 0.82 , respectively, using polynomial equation. The application of several indices indicating different components of the hydrological cycle integrates many factors that affect and trigger droughts, and thus can help in providing a wider realization of the characteristics of droughts on various water sections.
\end{abstract}

Keywords Hydrological drought $\cdot$ Meteorological drought $\cdot$ SPI $\cdot$ SPEI $\cdot$ SSI

\section{Introduction}

Drought is one of the most common natural hazards that have an adverse effect on agriculture and water resources. Several drought indices have been developed to control the

Sabereh Darbandi

sdarbandi.tabrizu@yahoo.com

Hana Salimi

hana.salimi.72@gmail.com

Esmail Asadi

esasadi@gmail.com

1 Water Engineering Department, University of Tabriz, Tabriz, Iran drought conditions. The drought indices have different characteristics and appropriate for specific environments. The physical relationship between the water cycle processes leads to the coordination of occurrence time and severity of hydrological and meteorological drought. Meteorological drought occurs rapidly, while hydrological drought occurs after a meteorological drought (Wilhite 2000). Drought indices such as PDSI (Palmer 1965), standardized evapotranspiration index (Vicente-Serrano et al. 2010) and standardized precipitation index (Mckee et al. 1993) are used extensively for monitoring the meteorological droughts over the world. Sims et al. (2002) studied the relationship between SPI with the soil moisture, which can determine the available water for plants and agriculture. The SDI is 
based on the standardized river flow and surface flow and its computational principles are similar to SPI (Shukla and Wood 2008). Bazrafshan et al. (2010) calculated the SPI and RDI in eight costal stations of Iran, including five stations with very humid climate (located on the coast of the Caspian Sea) and three stations with very dry climate (located on the Persian Gulf coast), that there is a correlation of more than 0.9 between SPI and RDI in all stations and Student $t$ test showed that there is no significant difference between two indices at a 5\% confidence level. Edossa et al. (2010) studied the drought characteristics in the Awash River basin of Ethiopia based on meteorological and hydrological drought variables. The SPI was used for temporal and spatial analysis of meteorological drought and river stream flow was applied to the hydrological drought analysis and the results showed that the hydrological drought has lag 7 months than meteorological drought. Vicente-Serrano et al. (2011) investigated the possible impacts of warming processes on drought and water resources in Spain and showed that the precipitation and evapotranspiration increased over the period of 1930-2006 and SPI and SPEI had the same results. Tigkas et al. (2012) used RDI and SDI to study the impacts of weather conditions on the meteorological and hydrological droughts in the period of 3-12 months. The results showed that a high correlation was between the RDI-9 and SDI-12. Azareh et al. (2014) calculated the SPI and SDI. The results showed that the relationship between the drought impact on stream flow of the Karaj dam basin and the relationship between hydrological and meteorological drought is significant at $99 \%$ confidence level. Tokarczyk and Szalinska (2014) calculated the SPI and SRI in two basins of Poland. The results showed that the meteorological drought often related to hydrological drought. Ahmadalipour et al. (2017) analyzed the meteorological and hydrological drought of Willamette river basin in the Northwest Pacific basin. They used the atmospheric global circulation model of the GCMs and downscaling model of CMIP5 in order to assess the impact of climate change and used PRMS distributed hydrological model for simulation of rainfall-runoff. Results show that the meteorological drought can begin and end quickly, while hydrological drought takes much longer to develop and then recover. Wu et al. (2017) studied the hydrological and meteorological drought relationships using SPI and SSI in the Jinjiang river basin in China with consideration the impact of a large reservoir. They used to run theory to determine the drought characteristics from 1960 to 2010 . They resulted that there is a nonlinear relationship between the hydrological and meteorological droughts. $\mathrm{Wu}$ et al. (2017) studied the effects of reservoir operation on the multiple correlations between the hydrological drought and meteorological droughts in the basin of the Dongjiang river in southern China (SPI) using monthly stream flow and precipitation data in 1960-2015 and the input and output stream flow of the Xinfengjiang reservoir in 1974-2009. The results showed that the reservoir operation from 1974 to 2015 has a positive impact on the short-term evolution of hydrological droughts ( 1 and 3 months). The aim of this present study is to investigate the dry and wet periods over three basins using the SPI, SPEI and SSI drought indices for long-term drought studies. The differences between three-index performances were discussed, and the relations between the indices were obtained using nonlinear models. The relationships between the indices are presented for the studied basins in the period of $1,3,6,9,12,24$ and 48 months. The main aim of this study is extraction of duration and severity of drought in the three watershed basins.

\section{Materials and methods}

\section{Study area and data}

In this research, three areas with several climates (dry, semiarid and wet) were used. The Lighvan watershed has the semiarid climate that is one of the most important sub-basins of Talkherood basin. It is in the province of East Azarbaijan, on the northern slopes of Sahand that extend between the geographic coordinates E longitude of $46^{\circ} 25^{\prime}-47^{\circ} 26^{\prime}$ and $\mathrm{N}$ latitude of $37^{\circ} 45^{\prime}$, Navroud basin has the wet climate that is one of the important watershed basins of the western province of Gilan in the city of Talesh between the E longitudes of $48^{\circ} 35^{\prime}-48^{\circ} 54^{\prime}$ and $\mathrm{N}$ latitudes of $37^{\circ} 36^{\prime}-37^{\circ} 45^{\prime}$ and originates in Alborz Mountain, which is part of Talesh Mountains and after joining the other sub-branches. The Seqez basin has the dry climate that climatology and hydrometric stations of Panbe dan valley were used that is located between the $\mathrm{E}$ longitude of $46^{\circ} 17^{\prime}$ and $\mathrm{N}$ latitude of $36^{\circ} 14^{\prime}$ from the equator. Figure 1 shows the geographic location of the meteorological and hydrometric stations, and Table 1 shows the geographic characteristics of the meteorological and hydrometric stations in studying basins. Table 2 presents annual statistics for each parameter stations.

\section{Characteristics of used indices}

\section{Standardized precipitation index (SPI)}

The standardized precipitation index (SPI) is a widely used index to characterize meteorological drought on a range of timescales. On short timescales, the SPI is closely related to soil moisture, while at longer timescales, the SPI can be related to groundwater and reservoir storage. The SPI can be compared across regions with markedly different climates. It quantifies observed precipitation as a standardized departure from a selected probability distribution function that models 


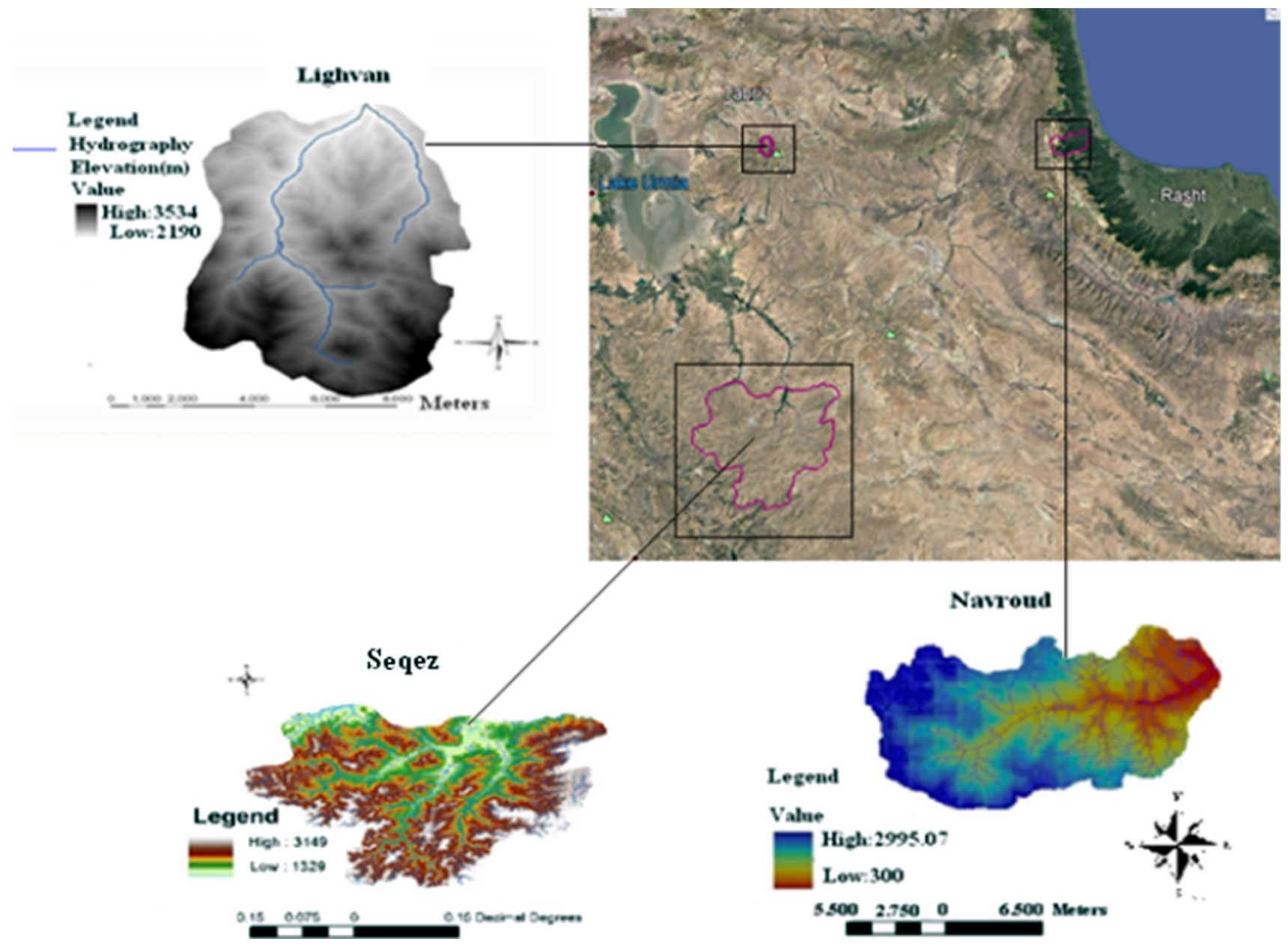

Fig. 1 Location of the study areas in Iran

Table 1 Information of hydrometric and meteorological stations

\begin{tabular}{|c|c|c|c|c|c|c|c|}
\hline Basin & Station & Type & Climate type & Area $\left(\mathrm{km}^{2}\right)$ & Elevation (m) & $\begin{array}{l}\text { Longitude } \\
\text { (degree) }\end{array}$ & Latitude (degree) \\
\hline \multirow[t]{2}{*}{ Navroud } & Navroud & Meteorological & Wet & 274 & 807 & 48.73 & 37.67 \\
\hline & Khalian & Hydrometric & & & 142 & 48.73 & 37.67 \\
\hline \multirow[t]{2}{*}{ Lighvan } & Lighvan & Meteorological & Dry and semiarid & 77 & 2279 & 46.43 & 37.83 \\
\hline & Lighvan & Hydrometric & & & 2200 & 46.43 & 37.83 \\
\hline \multirow[t]{2}{*}{ Seqez } & Seqez & Meteorological & Mediterranean mountainous & 4953.1 & 1522.8 & 46.26 & 36.25 \\
\hline & Panbe dan & Hydrometric & & & 1470 & 46.36 & 36.28 \\
\hline
\end{tabular}

the raw precipitation data (McKee et al. 1993). The raw precipitation data are typically fitted to a gamma or a Pearson type III distribution and then transformed to a normal distribution. The SPI values can be interpreted as the number of standard deviations by which the observed anomaly deviates from the long-term mean. The SPI can be calculated (Eq. 1) for differing periods of 1-36 months, using monthly precipitation data. In the operational community, the SPI has been recognized as the standard index that should be available worldwide for quantifying and reporting meteorological drought. Concerns have been raised about the utility of the SPI as a measure of changes in drought associated with climate change, as it does not deal with changes in evapotranspiration. Alternative indices that deal with evapotranspiration have been proposed. Ultimately, the SPI value is calculated by converting the cumulative probabilities based 
Table 2 Annual statistics for each parameter

\begin{tabular}{|c|c|c|c|c|}
\hline Basin & Parameter & $\begin{array}{l}\text { Evapotran- } \\
\text { spiration } \\
\text { (mm/day) }\end{array}$ & Discharge $\left(\mathrm{m}^{3} / \mathrm{s}\right)$ & $\begin{array}{l}\text { Pre- } \\
\text { cipitation } \\
(\mathrm{mm})\end{array}$ \\
\hline \multirow[t]{7}{*}{ Seqez } & $\begin{array}{l}\text { Number of } \\
\text { data }\end{array}$ & 300 & 300 & 300 \\
\hline & Average & 114.3 & 8.16 & 37.82 \\
\hline & Min & 20.65 & 0.044 & 0 \\
\hline & Max & 248.9 & 78.19 & 354.1 \\
\hline & $\begin{array}{l}\text { Standard } \\
\text { deviation }\end{array}$ & 63.81 & 11.8 & 43.65 \\
\hline & Skewness & 0.19 & 2.57 & 2.23 \\
\hline & Kurtosis & -1.33 & 8.7 & 9.77 \\
\hline \multirow[t]{7}{*}{ Ligvan } & $\begin{array}{l}\text { Number of } \\
\text { data }\end{array}$ & 300 & 300 & 300 \\
\hline & Average & 110.34 & 0.8 & 29.6 \\
\hline & Min & 24.52 & 0.078 & 0 \\
\hline & Max & 304.08 & 5.3 & 143.3 \\
\hline & $\begin{array}{l}\text { Standard } \\
\text { deviation }\end{array}$ & 60.93 & 0.86 & 25.39 \\
\hline & Skewness & 0.36 & 2.6 & 1.22 \\
\hline & Kurtosis & -1.03 & 7.7 & 1.26 \\
\hline \multirow[t]{7}{*}{ Navroud } & $\begin{array}{l}\text { Number of } \\
\text { data }\end{array}$ & 300 & 300 & 300 \\
\hline & Average & 65.80 & 1.86 & 56.72 \\
\hline & Min & 13.54 & 0.7 & 2 \\
\hline & Max & 167.9 & 7.08 & 271.9 \\
\hline & $\begin{array}{l}\text { Standard } \\
\text { deviation }\end{array}$ & 45.2 & 0.94 & 36.37 \\
\hline & Skewness & 0.07 & 1.94 & 1.47 \\
\hline & Kurtosis & -1.5 & 5 & 4.4 \\
\hline
\end{tabular}

on the Gamma distribution to a standard normal distribution (McKee et al. 1993). The SPI can be calculated as follows:

$\mathrm{SPI}=s \frac{t-\left(c_{2} t+c_{1}\right) t+c_{0}}{\left(\left(d_{3} t+d_{2}\right)+d_{1}\right)+1} \quad t=\sqrt{\ln \frac{1}{H(X)^{2}}}$

$G(x)=\frac{1}{\beta^{\gamma} \Gamma(\gamma)_{0}} \int_{0}^{\mathrm{x}} X^{\gamma-1} \mathrm{e}^{\frac{-x}{\beta}} \mathrm{d} x, \quad X>0(\gamma)=\int_{0}^{\infty} X^{\gamma-1} \mathrm{e}^{-\mathrm{x}} \mathrm{d} x$

where $x$ denotes precipitation value; $\mathrm{b}$ and $\mathrm{c}$ represent the scale and shape parameters of the $\mathrm{C}$ function; $\mathrm{S}$ is positive and negative coefficients; and $c_{0}, c_{1}, c_{2}$ and $d_{1}, d_{2}, d_{3}$ are calculated parameters. Their values are displayed as follows: $c_{0}=2.515517, c_{1}=0.802853, c_{2}=0.010328, d_{1}=1.432788$, $d_{2}=0.189269$ and $d_{3}=0.001308$. $G(x)$ denotes the probability distribution of precipitation. When $G(x)>0.5$, then $H(x)=1-G(x)$ and $S=1$; otherwise, $H(x)=G(x)$ and $S=-1$.
Standardized precipitation-evapotranspiration index (SPEI)

FAO-56 illustrated Penman-Monteith's method as the standard method for calculating the reference evapotranspiration (Alan et al. 1998):

$\mathrm{ET}_{0}=\frac{0.408 \Delta\left(R_{\mathrm{n}}-G\right)+\gamma\left[\frac{890}{T+273}\right] U_{2}\left(e_{\mathrm{a}}-e_{\mathrm{d}}\right)}{\Delta+\gamma\left(1+0.34 U_{2}\right)}$

where $\mathrm{ET}_{0}$ represents the evapotranspiration of plant $\left(\mathrm{mm} /\right.$ day), $R_{\mathrm{n}}$ is the net radiation on vegetation cover (mega$\mathrm{joul} / \mathrm{m}^{2} /$ day), $\mathrm{T}$ is the average air temperature $(\mathrm{C}), \mathrm{U}_{2}$ introduces the wind speed at $2 \mathrm{~m}$ above the ground level $(\mathrm{m} / \mathrm{s})$, $e_{\mathrm{a}}-e_{\mathrm{d}}$ shows the pressure shield shortage at $2 \mathrm{~m}(\mathrm{kPa}), \Delta$ is determined by the slope of the vapor pressure curve $(\mathrm{kPa} / \mathrm{C})$, $\gamma$ is the psychometric coefficient $(\mathrm{kPa} / \mathrm{C})$ and $G$ is the heat flux into the soil $\left(\mathrm{Mj} / \mathrm{m}^{2} /\right.$ day $)$.

The SPEI is presented by Vicente-serrano et al. (2011) and it has been used in numerous studies; also calculation method involves the equilibrium of the climate and considers the role of the temperature in the drought evaluation. Previously, the palmer drought severity index (PDSI) uses the readily available temperature and precipitation data to estimate relative dryness (Palmer 1965). It is a standardized index that spans -10 (dry)- +10 (wet) (Vicente-serrano et al. 2010). It has been reasonably successful at quantifying long-term drought. As it uses temperature data and a physical water balance model, it can capture the basic effect of global warming on drought through changes in potential evapotranspiration. Some studies have compared different methods for calculating PET (Sheffield et al. 2012) and it has been shown that the Penman-Monteith equation approximates net evapotranspiration (ET), requiring as input daily mean temperature, wind speed, relative humidity and solar radiation (Allen et al 1998). Therefore, in this study the calculation of SPEI is based on Penman-Monteith equation with Hargreaves-Samani correction that described in FAO56 (Allen et al. 1998). The PM method chosen by the World Meteorological Organization (WMO) that has been proposed as the standard method for PET estimation, and its accuracy has been proved by the need of less data.

The monthly values of the reference plant evapotranspiration are calculated based on the climatological data and using Eq. (3). In the next step, the difference between the precipitation $(P)$ and evapotranspiration $\left(\mathrm{ET}_{0}\right)$ for the ith month can be calculated:

$D_{i}=P_{i}-\mathrm{PET}_{0 i} \quad i=1,2, \ldots . ., N$

In order to calculate SPEI in different timescales, it is necessary to form series at different time steps (Paulo et al. 2003): 


$$
\begin{aligned}
x_{i . j}^{k} & =\sum_{l=13-\mathrm{k}+\mathrm{j}}^{12} w_{i-1+l}+\sum_{l=1}^{j} w_{i, l} & \text { if } \quad j<k \\
x_{i, j}^{k} & =\sum_{l=\mathrm{j}-k+1}^{j} w_{i, l} & \text { if } \quad j \geq k
\end{aligned}
$$

where $w_{i, 1}$ is the value of $\mathrm{D}_{\mathrm{i}}$ or the water requirement in the first month of the year ( $\mathrm{mm})$. The SPEI is used at various times for monitoring the agricultural and hydrological droughts (komuscu, 1999). The SPEI calculating, like the SPI method, requires estimating cumulative probability values of $D_{i}$ by fitting a probability function. Now, $D_{i}$ values from the lower bound lead to the negative values and two-parameter probability functions cannot be selected. In this research, with goodness-of-fit test, extreme value distribution function was selected for $D_{i}$ series and the drought analysis was performed on time steps of 3, 6, 9, 12, 24 and 48 months. The crossover probability values of $D_{i}$ series are converted to the standardize function with mean zero and standard deviation of 1, which will be equal to the values of SPEI (Vicente-Serrano 2006):

SPEI $=W-\frac{C_{0}+C_{1} W+C_{2} W^{2}}{1+\mathrm{d}_{1} W+\mathrm{d}_{2} W^{2}+\mathrm{d}_{3} W^{3}}$

$W=\sqrt{-2 \operatorname{Ln}(p)}$ for $P \leq 0.5$

in which $P$ is the probability of exceeding the $D$ and $P=1-F(x)$ values. If the value of $P$ is greater than 0.5 , then the value of $P$ is replaced with $1-P$ and SPEI sign is changed.

\section{Standard stream flow index (SSI)}

The researchers developed the standard hydrological drought indices similar to the meteorological drought indices. Two known hydrological drought indices, which include standard stream flow index and stream flow drought index, have the same theoretical background (Shukla and Wood 2008). Both indices attempt to convert the monthly flow into a standard normal distribution (mean zero and variance of one, similar to SPI method) and calculate the hydrological drought index. In this research, the standardized flow index was used. The SSI is calculated based on nonparametric approach. Therefore, in order to calculate this index, exactly the same calculation process is repeated; only with the difference that instead of precipitation data, stream flow data are used as input data. For this index, as same SPI, the gamma distribution is appropriate. This method is simple and similar to SPI method. The cumulative flow values for each month are individually evaluated, and SSI is calculated for each month. The classification of the indices used in this study is shown in Table 3.
Table 3 Classification of different states of drought indices (McKee et al. 1993)

\begin{tabular}{ll}
\hline Drought category & SPI, SPEI, SSI \\
\hline Extremely wet & $>2$ \\
Very wet & $1.5-1.99$ \\
Moderately wet & $1-1.49$ \\
Near normal & $-0.99-0.99$ \\
Moderately dry & -1 to -1.49 \\
Severely dry & -1.5 to -1.99 \\
Extremely dry & -2 and less \\
\hline
\end{tabular}

\section{Evaluation criteria}

In this study, Pearson correlation coefficient (Cercal Pearson) and crossover correlation function (Chang et al. 1997) were used to evaluate the comparative indices. The coefficient of determination (Draper and Smith 1998) was used in order to evaluate the efficiency of mathematical relations between indices. Table 4 shows the equations of the accuracy indices.

\section{Drought identification using run theory}

Yevjevich (1967) suggested the run theory (Fig. 2), which has been used often in time series of anomalous hydrological events and was used to identify drought components and survey their statistical properties (Mishra and Desai 2005; Nam et al. 2015). A drought phenomenon is defined as a continuing sequence of months $(t)$ with drought index value $\left(X_{\mathrm{t}}\right)$ less than a selected threshold $\left(X_{0}\right)$. A drought event is defined by the following components, which can be applied for mathematical analysis of drought (Fig. 2). Drought beginning time $\left(T_{\mathrm{s}}\right)$ is the onset month of a drought event. Drought ending time $\left(T_{\mathrm{e}}\right)$ shows the date when the shortage of water becomes sufficiently small so that the drought no longer persists. Drought duration $(D)$ is the time period between the starting and ending of a drought. Drought severity $(S)$ is obtained by the cumulative shortage of the drought parameter below the critical level. Drought intensity $(I)$ is calculated as the proportion of drought severity and the drought duration. Figure 2 shows the characteristics of the drought using the run theory (Yevjevich 1967).

\section{Results and discussion}

\section{Comparative evaluation of the meteorological drought and hydrological drought}

For comparative evaluation of the meteorological and hydrological drought indices, graphs of SPI and SSI, and

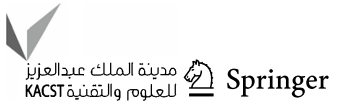


Table 4 Equations of the accuracy indices

\begin{tabular}{lll}
\hline Accuracy index & Equation & Range \\
\hline Pearson correlation coefficient & $R=\frac{\left(\sum_{i=1}^{t}\left(x_{i} y_{i}\right)-\left(\sum_{i=1}^{t} x_{i}\right)\left(\sum_{i=1}^{t} y_{i}\right)\right.}{\sqrt{\left[n\left(\sum_{i=1}^{t}\left(x_{i}^{2}\right)\right)-\left(\sum_{i=1}^{t} x_{i}\right)^{2}\right]\left[n\left(\sum_{i=1}^{t}\left(y_{i}^{2}\right)\right)-\left(\sum_{i=1}^{t} y_{i}\right)^{2}\right]}}$ & $-1 \leq R \leq+1$ \\
Crossover correlation function & $R=\frac{\sum_{i}^{n=1}\left(x_{(i)}-\bar{x}\right)\left(y_{(i-d)}-\bar{y}\right)}{\sqrt{\sum_{i=1}^{n}\left(x_{(i)}-\bar{x}\right) \sqrt{\sum_{i=1}^{n}\left(x_{(i)}-\bar{x}\right)^{2}} \sqrt{\sum_{i=1}^{n}\left(y_{(i-d)}-\bar{y}\right)^{2}}}}$ & $-1 \leq R \leq+1$ \\
$R^{2}$ & $R^{2}=\left[\frac{\sum_{N}^{l=1}\left(x_{i}-\bar{x}\right)\left(y_{i}-\bar{y}\right)}{\sqrt{\sum_{N}^{i=1}\left(x_{i}-\bar{x}\right)^{2}\left(\sum_{N}^{i=1}\left(y_{\mathrm{i}}-\bar{y}\right)\right)^{2}}}\right]^{2}$ & \\
\hline
\end{tabular}

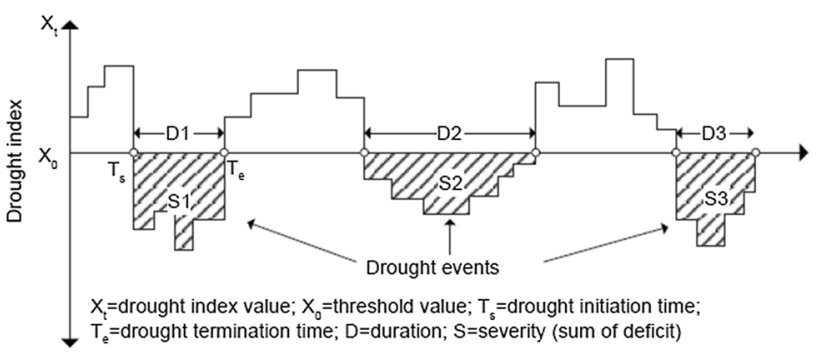

Fig. 2 Definition of drought characteristics including duration and magnitude using the run theory (Yevjevich 1967)

SPEI and SSI in the three studied watershed basins are plotted (1992-2016). Figure 3 shows the Pearson correlation between SPI, SPEI and SSI at 1-48 months' time steps. Significant positive correlation means that the decrease in the precipitation causes the decrease in the stream flow; in other words, meteorological droughts in the watershed basin caused a hydrological drought throughout the basin. There is a good correlation between 48 months of SSI-SPI and SSI-SPEI in Navroud basin. The maximum correlation between 24 months of SSI-SPI and 12 months of SPEI-SSI is observed in Seqez basin.

Figure 3 shows the Pearson correlation between SPISPEI and SSI-SSI drought indices during the period of 1-48 months in the studied basins.

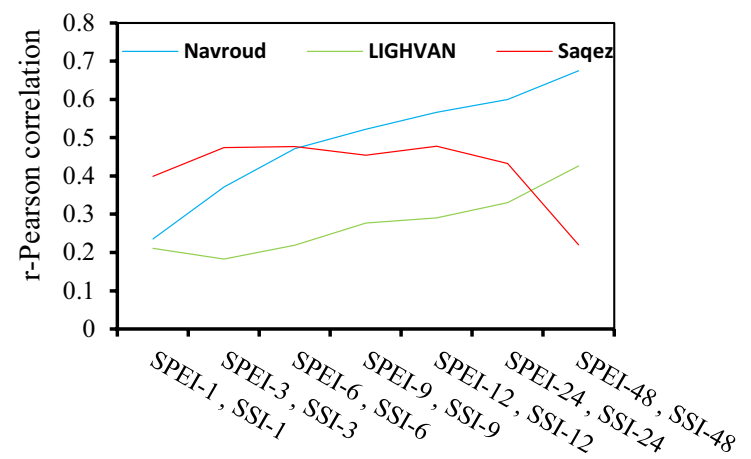

Fig. 3 Pearson correlation coefficients between indices for 1-48 months
Based on the results, the highest correlation coefficient in the Navroud basin is between SPI and SSI at lags 3 and 4 in the 48-month period with the values of 0.730 and 0.731 , respectively. It means that the meteorological drought in the Navroud basin affects the hydrological drought at lags 3 and 4 and the maximum correlation observed for a period of 48 months and between SPEI and SSI at lags 1 and 2 with the values of 0.687 and 0.686 , respectively. In other words, the hydrological drought in Navroud basin responds to the meteorological drought at lags 1 and 2. Figure 4 shows the crossover correlation between SSI-SPI and SSI-SPEI simultaneously. As shown in Fig. 4, the maximum correlation observed in Navroud basin in the 48-month period and good crossover coefficient was between SPI and SSI with a value of 0.527 at lag 7 in the period of 48 -month period. It means that the hydrological drought has occurred to the meteorological drought with the 7 lag months. These results similar to what was found by Edossa et al. (2010) in the Awash river basin of Ethiopia. It means that the meteorological and hydrological droughts occur in a basin at lags 7 months. Also, Fig. 4 shows the good correlation in the 48-month period. According to the results, in Seqez basin, the maximum correlation coefficient between SPI and SSI was obtained instantaneously in the 24-month period with the value of 0.614 . This means that the meteorological drought in the region affects immediately the surface water and the crossover coefficient between SPEI and SSI in this

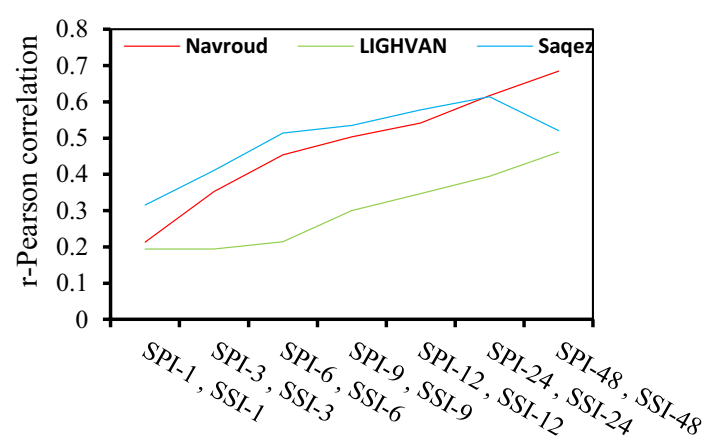



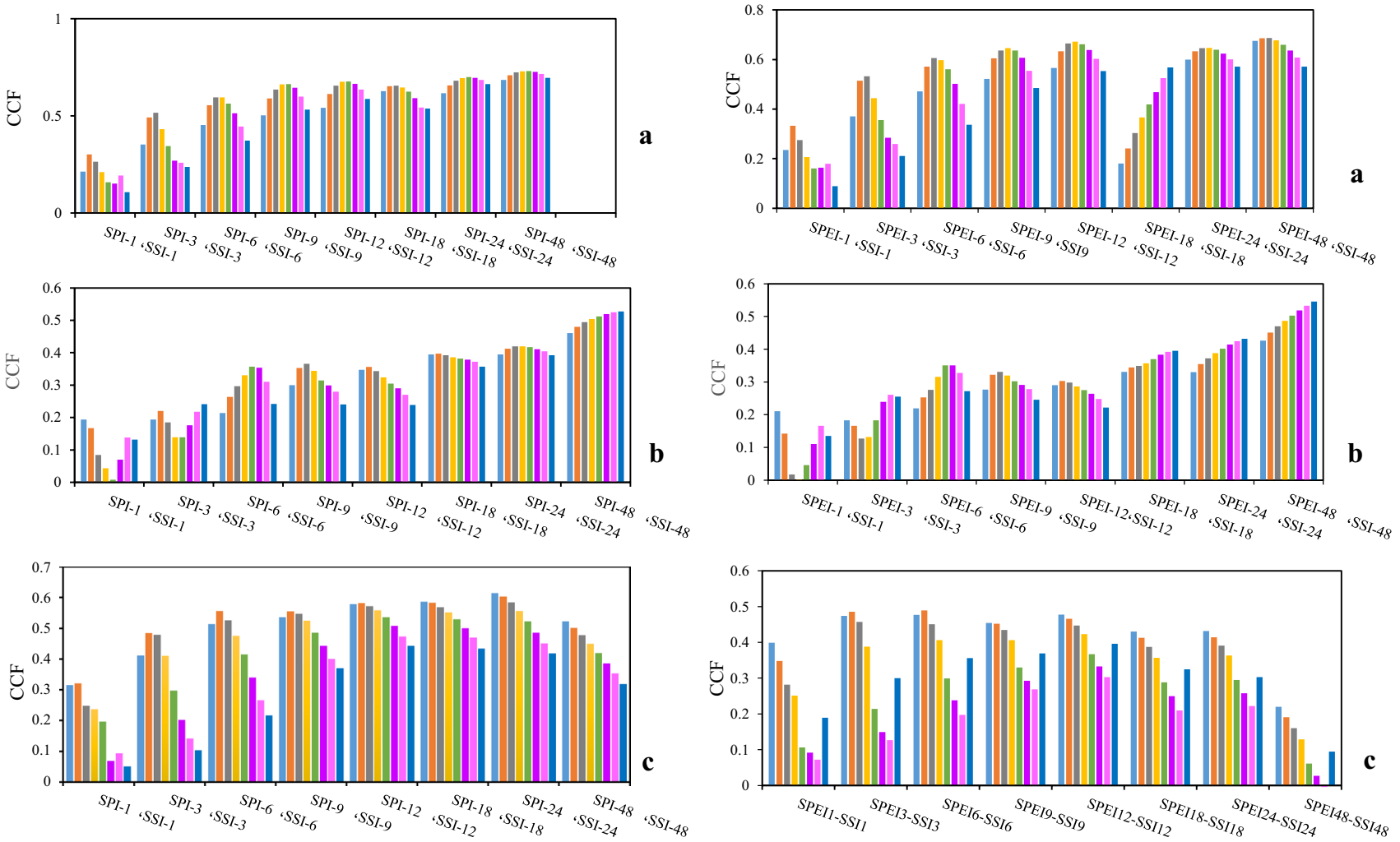

$=$ NOLAG $=$ LAG $1=L A G 2=\operatorname{LAG} 3=\operatorname{LAG} 4=\operatorname{LAG} 5=$ LAG $6=L A G ?$

Fig. 4 Crossover correlation between indices simultaneously in the a Navroud, b Lighvan, c Seqez

basin was observed in the 6-month period at lag 1 month with the value of 0.489 . In other words, the meteorological drought in the region is affected the surface water resources at lag 1 month.

Figure 5 Shows the time series of drought indices with high cross-correlation coefficient in the study areas.

\section{Extraction of relationship between the indices}

In this research, SPI, SSI and SPEI from 1992 to 2016 were calculated and the characteristics of meteorological and hydrological drought were extracted using the Run theory. The relations between hydrological droughts and meteorological droughts were obtained (Table 5) using the nonlinear models (polynomial, exponential and logarithmic). The relationships between the indices are presented for the studied basins in the period of 1, 3, 6, 9, 12, 24 and 48 months. The relations between the duration and severity of drought have been more accurate in the period of 9 months in the Navroud watershed basin. The most significant events are SPI-9 with the duration of 57 months and the severity of 34.7, SPEI-9 with the duration of 34 months and the severity of 28.09 and SSI-9 with the duration of 41 months and the severity of 30.2. The good $R^{2}$ between the duration and severity of
SPI-9 and SSI-9 is 0.8 and 0.92 , respectively, for polynomial equations. The maximum determination coefficient of duration and severity of SPEI-9 and SSI-9 is 0.72 and 0.82, respectively, using polynomial equation. Also Table 4 shows that a polynomial function is better than to other functions in Navroud hydrometric station. The calculated relations between the duration and severity of indices show that the good accuracy is in the period of 12 months in the watershed basin. The most important events are SPI-12 with the duration of 88 months and the severity of 100.98, SPEI-12 with the duration of 88 months and the severity of 93.11 and SSI-12 with the duration of 47 months and severity of 60.22. According to Table 4, the highest accuracy between SPI-12 and SSI-12 is related to exponential and logarithmic equations with $R^{2}=0.99$ and $R^{2}=0.92$, respectively, and the highest $R^{2}$ between the duration and severity of SPEI12 and SSI-12 is related to the logarithmic and exponential equations and equals to 0.9. According to the obtained equations in different time periods, it was resulted that the highest accuracy was observed in the relationship between the meteorological and hydrological drought characteristics in the watershed basin of Seqez for a period of 6 months. The most important events are SPI- 6 with the duration of 36 months and the severity of 33.8, SPEI- 6 with the duration 

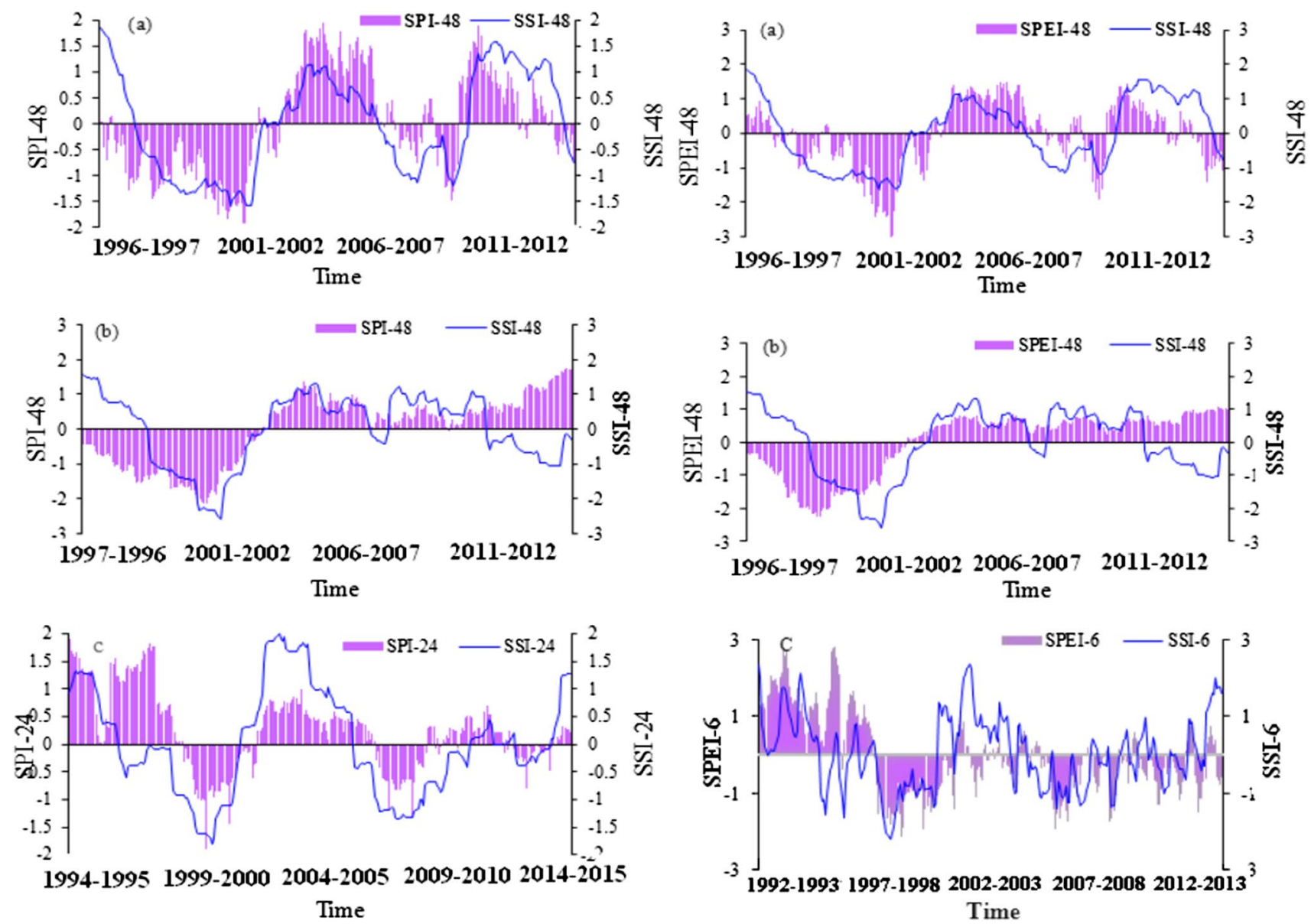

Fig. 5 Time series of drought indices with high cross-correlation coefficient in the a Navroud, b Lighvan, c Seqez

of 56 months and the severity of 34.8, and SSI-6 with the duration of 37 months and the severity of 41.22 . Regarding the severity and duration of SPI-6 and SSI-6, the highest accuracy was obtained by polynomial equation with the determination coefficient of 0.98 and 0.95 , respectively, and the highest $R^{2}$ between the severity and duration of SPEI- 6 and SSI-6 for the exponential and polynomial equations is 0.98 and 0.79 , respectively.

\section{Conclusion}

Iran is in the temperate (arid and semiarid) zone of the world. The use of drought indices allowed studying and analysis of the characteristics and propagation behaviors of droughts using SPI, SPEI and SSI for extracting the time series of dry and wet periods during past periods. From the computation and analysis of these indices at meteorological and hydrometric stations in study areas, we observed that droughts from 1992 to 2016 were depicted by these indices based on the meteorological and hydrological data. The SPEI is more appropriate than the SPI for applications examining of drought variability in study areas because it uses precipitation and evapotranspiration data. The results showed that precipitation plays a significant role in explaining the time variations of the droughts and temperature increasing also has a significant effect on the water shortage, especially in long-term periods in the region. The Pearson correlation matrix and crossover correlation show that SPI drought index is better than SPEI drought index in the Navroud basin because Navroud basin is wet zone and with less evapotranspiration. However, the SSI hydrological drought index responds faster to SPEI drought index (lags 1 and 2) compared to SPI (lags 3 and 4). In the arid and semiarid areas, because of much evapotranspiration, the SPEI is better than the SPI and it was found that SSI has responded to both SPI and SPEI in the watershed basin at lag 7. Extracting the nonlinear model between the meteorological and hydrological drought shows that there is a relationship between the hydrological drought response to the meteorological drought. In general, the application of several indices indicating different components of the hydrological cycle integrates many factors that affect and trigger droughts, and thus can help 
Table 5 Relationships of hydrological drought and meteorological drought

\begin{tabular}{|c|c|c|c|c|c|}
\hline Station & Index & Duration & $R^{2}$ & Magnitude & $R^{2}$ \\
\hline \multirow[t]{8}{*}{ Navroud } & \multirow[t]{4}{*}{ SPI-9, SSI-9 } & $\mathrm{SSI}_{\mathrm{D}}=28.8 \mathrm{SPI}_{\mathrm{D}}-0.0122$ & 0.6 & $\mathrm{SSI}_{\mathrm{M}}=10.9 \mathrm{SPI}_{\mathrm{M}}^{0.192}$ & $\mathbf{0 . 5 7}$ \\
\hline & & $\mathrm{SSI}_{\mathrm{D}}=23.4 \mathrm{e}^{0.0067} \mathrm{SPI}_{\mathrm{D}}$ & 0.5 & $\mathrm{SSI}_{\mathrm{M}}=12.4 \mathrm{e}_{\mathrm{M}}^{0.0173 \mathrm{SPI}}$ & 0.4 \\
\hline & & $\begin{array}{l}\mathrm{SSI}_{\mathrm{D}}=49.5-6.44 \mathrm{SPI}_{\mathrm{D}}+0.295 \mathrm{SPI}_{\mathrm{D}}^{2}-0.00328 \\
\mathrm{SPI}_{\mathrm{D}}{ }^{3}\end{array}$ & 0.8 & $\begin{array}{l}\mathrm{SSI}_{\mathrm{M}}=12.7-2.61 \mathrm{SPI}_{\mathrm{M}}+0.25 \mathrm{SPI}_{\mathrm{M}}{ }^{2}-0.00491 \\
\mathrm{SPI}_{\mathrm{M}}{ }^{3}\end{array}$ & 0.92 \\
\hline & & $\mathrm{SSI}_{\mathrm{D}}=28.5-0.245 \mathrm{LN}\left(\mathrm{SPI}_{\mathrm{D}}\right)$ & 0.6 & $\mathrm{SSI}_{\mathrm{M}}=10.5+3.1 \mathrm{LN}\left(\mathrm{SPI}_{\mathrm{M}}\right)$ & 0.6 \\
\hline & \multirow[t]{4}{*}{ SPEI-9, SSI-9 } & $\mathrm{SSI}_{\mathrm{D}}=4.5 \mathrm{SPEI}_{\mathrm{D}}^{0.597}$ & 0.48 & $\mathrm{SSI}_{\mathrm{M}}=2.1 \mathrm{SPEI}_{\mathrm{M}}^{0.75}$ & 0.57 \\
\hline & & $\mathrm{SSI}_{\mathrm{D}}=11.6 \mathrm{e}^{0.036 \mathrm{SPEI}}{ }_{\mathrm{D}}$ & 0.44 & $\mathrm{SSI}_{\mathrm{M}}=7.6 \mathrm{e}^{0.0433} \mathrm{SPEI}_{\mathrm{M}}$ & 0.42 \\
\hline & & $\begin{array}{l}\mathrm{SSI}_{\mathrm{D}}=-17.5+8.17 \mathrm{SPEI}_{\mathrm{D}}-0.504 \\
\mathrm{SPEI}_{\mathrm{D}}^{2}+0.00938 \mathrm{SPEI}_{\mathrm{D}}^{3}\end{array}$ & 0.72 & $\begin{array}{l}\mathrm{SSI}_{\mathrm{M}}=3.4-1.64 \mathrm{SPEI}_{\mathrm{M}}+0.313 \mathrm{SPEI}_{\mathrm{M}}^{2}-0.00835 \\
\mathrm{SPEI}_{\mathrm{M}}{ }^{3}\end{array}$ & 0.82 \\
\hline & & $\mathrm{SSI}_{\mathrm{D}}=-10.69+13 \mathrm{LN}\left(\mathrm{SPEI}_{\mathrm{D}}\right)$ & 0.5 & $\mathrm{SSI}_{\mathrm{M}}=-12.6+11.1 \mathrm{LN}\left(\mathrm{SPEI}_{\mathrm{M}}\right)$ & 0.63 \\
\hline \multirow[t]{8}{*}{ Lighvan } & \multirow[t]{4}{*}{ SPI-12, SSI-12 } & $\mathrm{SSI}_{\mathrm{D}}=4.77 \mathrm{SPI}_{\mathrm{D}}^{0.511}$ & 0.91 & $\mathrm{SSI}_{M}=2.8 \mathrm{SPI}_{M}^{0.665}$ & 0.99 \\
\hline & & $\mathrm{SSI}_{\mathrm{D}}=13.7 \mathrm{e}^{0.0139 \mathrm{x}}$ & 0.90 & $\mathrm{SSI}_{\mathrm{M}}=7.28 \mathrm{e}^{0.02092} \mathrm{SPI}_{M}$ & 0.98 \\
\hline & & $\mathrm{SSI}_{\mathrm{D}}=-19+14.8 \mathrm{LN}\left(\mathrm{SPI}_{\mathrm{D}}\right)$ & 0.92 & $\mathrm{SSI}_{\mathrm{M}}=0.74+0.906 \mathrm{SPI}_{\mathrm{M}}+0.081 \mathrm{SPI}_{\mathrm{M}}^{2}$ & 0.98 \\
\hline & & $\underset{2}{\mathrm{SSI}_{\mathrm{D}}}=\left(4.28 \times 10^{-12}\right)-5.56 \mathrm{SPI}_{\mathrm{D}}+0.742\left(\mathrm{SPI}_{\mathrm{D}}\right.$ & 0.90 & $\mathrm{SSI}_{\mathrm{M}}=-14.5+15.5 \mathrm{LN}\left(\mathrm{SPI}_{\mathrm{M}}\right)$ & 0.94 \\
\hline & \multirow[t]{4}{*}{ SPEI-12, SSI-12 } & $\mathrm{SSI}_{\mathrm{D}}=7.22 \mathrm{SPI}_{\mathrm{D}}^{0.422}$ & 0.70 & $\mathrm{SSI}_{\mathrm{M}}=4.46 \mathrm{SPEI}_{\mathrm{M}}^{0.573}$ & 0.99 \\
\hline & & $\mathrm{SSI}_{\mathrm{D}}=17.1 \mathrm{e}^{0.0118 \mathrm{SPI}} \mathrm{D}$ & 0.68 & $\mathrm{SSI}_{\mathrm{M}}=7.56 \mathrm{e}^{0.0233} \mathrm{SPEI}_{\mathrm{M}}$ & 0.98 \\
\hline & & $\mathrm{SSI}_{\mathrm{D}}=\left(4.27 \times 10^{-11}\right)-3.5 \mathrm{SPI}_{\mathrm{D}}+0.581 \mathrm{SPI}_{\mathrm{D}}^{2}$ & 0.67 & $\mathrm{SSI}_{\mathrm{M}}=-0.968+9.45 \mathrm{SPEI}_{\mathrm{M}}-1.8 \mathrm{SPEI}_{\mathrm{M}}^{2}$ & 0.98 \\
\hline & & $\mathrm{SSI}_{\mathrm{D}}=-12.1+1.34 \mathrm{LN}\left(\mathrm{SPI}_{\mathrm{D}}\right)$ & 0.99 & $\mathrm{SSI}_{\mathrm{M}}=-2.25+\mathrm{LN}\left(\mathrm{SPEI}_{\mathrm{M}}\right)$ & 0.91 \\
\hline \multirow[t]{8}{*}{ Seqez } & \multirow[t]{4}{*}{ SPI-6, SSI-6 } & $\mathrm{SSI}_{\mathrm{D}}=1.93 \mathrm{SPI}_{\mathrm{D}}^{8.27}$ & 0.77 & $\mathrm{SSI}_{\mathrm{M}}=0.755 \mathrm{SPI}_{\mathrm{M}}^{1.14}$ & 0.97 \\
\hline & & $\mathrm{SSI}_{\mathrm{D}}=7.17 \mathrm{e}^{0.0461 \mathrm{SPI}}{ }_{\mathrm{D}}$ & 0.89 & $\mathrm{SSI}_{\mathrm{M}}=4.82 \mathrm{e}^{6.53 \mathrm{SPI}}{ }_{\mathrm{M}}$ & 0.62 \\
\hline & & $\begin{array}{l}\mathrm{SSI}_{\mathrm{D}}=19.7-3.77 \mathrm{SPI}_{\mathrm{D}}+0.32 \mathrm{SPI}_{\mathrm{D}}{ }^{2}-0.00556 \\
\mathrm{SPI}_{\mathrm{D}}{ }^{3}\end{array}$ & 0.95 & $\begin{array}{l}\mathrm{SSI}_{\mathrm{M}}=4.7-0.6 \mathrm{SPI}_{\mathrm{M}}+0.123 \mathrm{SPI}_{\mathrm{M}}^{2}-0.00216 \\
\mathrm{SPI}_{\mathrm{M}}{ }^{3}\end{array}$ & 0.98 \\
\hline & & $\mathrm{SSI}_{\mathrm{D}}=-17+14.6 \mathrm{LN}\left(\mathrm{SPI}_{\mathrm{D}}\right)$ & 0.88 & $\mathrm{SSI}_{\mathrm{M}}=-13.3+13.1 \mathrm{LN}\left(\mathrm{SPI}_{\mathrm{M}}\right)$ & 0.78 \\
\hline & \multirow[t]{4}{*}{ SPEI-6, SSI-6 } & $\mathrm{SSI}_{\mathrm{D}}=0.15 \mathrm{X}^{1.4}$ & 0.77 & $\mathrm{SSI}_{\mathrm{M}}=0.393 \mathrm{SPEI}_{\mathrm{M}}{ }^{1.2}$ & 0.98 \\
\hline & & $\mathrm{SSI}_{\mathrm{D}}=5.17 \mathrm{e}^{0.0366 \mathrm{X}}$ & 0.76 & $\mathrm{SSI}_{\mathrm{M}}=5.16 \mathrm{e}^{0.0403 \mathrm{SPEI}} \mathrm{M}$ & 0.9 \\
\hline & & $\mathrm{SSI}_{\mathrm{D}}=16.3-2.33 \mathrm{X}+0.11 \mathrm{X}^{2}-0.00111 \mathrm{X}^{3}$ & 0.79 & $\mathrm{SSI}_{\mathrm{M}}=-1.93+0.352 \mathrm{SPEI}_{\mathrm{M}}+0.031 \mathrm{SPEI}_{\mathrm{M}}{ }^{2}$ & 0.94 \\
\hline & & $\mathrm{Y}=-29.4+15.4 \mathrm{LN}(\mathrm{X})$ & 0.6 & $\mathrm{SSI}_{\mathrm{M}}=-36.9+19 \mathrm{LN}\left(\mathrm{SPEI}_{\mathrm{M}}\right)$ & 0.96 \\
\hline
\end{tabular}

in providing a wider realization of the characteristics of droughts on various water sections.

Funding The authors have no funding to report.

\section{Compliance with ethical standards}

Conflict of interest The authors have no conflicts of interest to declare.

Open Access This article is licensed under a Creative Commons Attribution 4.0 International License, which permits use, sharing, adaptation, distribution and reproduction in any medium or format, as long as you give appropriate credit to the original author(s) and the source, provide a link to the Creative Commons licence, and indicate if changes were made. The images or other third party material in this article are included in the article's Creative Commons licence, unless indicated otherwise in a credit line to the material. If material is not included in the article's Creative Commons licence and your intended use is not permitted by statutory regulation or exceeds the permitted use, you will need to obtain permission directly from the copyright holder. To view a copy of this licence, visit http://creativecommons.org/licenses/by/4.0/.

\section{References}

Ahmadalipour A, Mirzakhani H, Demiral MC (2017) A comparative assessment of projected meteorological and hydrological droughts: elucidating the role of temperature. J Hydrol 553:785-797

Allen RG, Pereira LS, Raes D, Smith M (1998) Crop evapotranspiration- guidelines for computing crop water requirements FAO irrigation and drainage paper 56. FAO Rome 300(9):D05109

Azareh A, Rahdari MR, Rafiei-Sardoi E, Azariya-Moghadam F (2014) Investigating the relationship between hydrological and meteorological droughts in the Karaj dam Basin. Eur J Exp Biol 4(3):102-107

Bazrafshan J, Hejabi S, Habibi Nokhandan M (2010) Is the SPI sufficient for monitoring meteorological droughts in extreme costal climates of Iran? Adv Nat Appl Sci 4(3):345-351

Chang PY, Hao E, Patt YN (1997) Target prediction for indirect jumps. ACM SIGARCH Computer Archit News 25(2):274-283

Draper NR, Smith H (1998) Applied Regression Analysis. Wiley-Interscience. ISBN 978-0-471-17082-2

Edossa DC, Babel MS, Gupta AD (2010) Drought analysis in the Awash river basin. Ethiop Water Resour Manag 24(7):1441-1460

Komuscu AU (1999) Using the SPI to analyze spatial and temporal patterns of drought in Turkey. Drought Net News 11:7-13 
Mishra AK, Desai VR (2005) Drought forecasting using stochastic models. Stoch Env Res Risk Assess 19:326-339

Mckee TB, Doesken NJ, leist J (1993) The relationship of drought frequency and duration to time scales. Preprints 8th Conference on Applied Climatology. 17:179-184

Nam WH, Hayes MJ, Svoboda MD, Tadesse T, Wilhite DA (2015) Drought hazard assessment in the context of climate change for South Korea. Agric Water Manag 160:106-117

Palmer WC (1965) Meteorological drought Research Paper No 45. US Department of Commerce Weather Bureau, Washington, pp 59

Paulo AA, Pereira LS, Matias PG (2003) Analysis of local and regional droughts in southern Portugal using the theory of runs and the standardised precipitation index. In: Rossi G, Cancelliere A (eds) Tools for drought mitigation in mediterranean regions. Springer, 44:55-78

Sheffield J, Wood EF, Roderick ML (2012) Little change in global drought over the past 60 years. Nature 491(7424):435-438

Shukla SH, Wood AW (2008) Use of a standardized runoff index for characterizing hydrologic drought. Geophys Res Lett 35(2):41-46

Sims AP, Nigoyi DS, Raman S (2002) Adopting indices for estimating soil moisture: a North Carolina case study. Geophys Res Lett 29(8):1-4

Tigkas D, Vangelis H, Tsakiris G (2012) Drought and climate change impact on streamflow in small watersheds. Sci Total Environ 440:33-41

Tokarczyk T, Szalinska W (2014) Combined analysis of precipitation and water deficit for drought hazard assessment. Hydrol Sci J 59(9):1675-1689
Vicente-Serrano SM (2006) Differences in spatial patterns of drought on different time scales: an analysis of the Iberian Peninsula. Water Resour Manage 20(1):37-60

Vicente-Serrano SM, Begueria S, Lopez-Moreno JI (2010) A multiscalar drought index sensitive to global warming: the standardized precipitation evapotranspiration index. J Clim 23(7):1696-1718

Vicente-Serrano SM, López-Moreno JI, Drumond A, Gimeno L, Nieto R, Morán-Tejeda E, Zabalza J (2011) Effects of warming processes on droughts and water resources in the NW Iberian Peninsula (1930-2006). Climate Res 48(2-3):203-212

Wilhite DA (2000) Drought as a natural hazard: concepts and definitions. drought, a global assessment. Natl Drought Mitig Center $1: 3-18$

Wu J, Chen X, Yao H, Gao L, Chen Y, Liu M (2017) Non-linear relationship of hydrological drought responding to meteorological drought and the impact of a large reservoir. J Hydrol 551:495-507

Yevjevich VM (1967) An objective approach to definitions and investigations of continental hydrologic droughts. Hydrology papers (Colorado State University); No. 23

Publisher's Note Springer Nature remains neutral with regard to jurisdictional claims in published maps and institutional affiliations. 